\title{
A global ab initio dipole moment surface for methyl chloride
}

\author{
Alec Owens ${ }^{\mathrm{a}, \mathrm{b}}$, Sergei N. Yurchenko ${ }^{\mathrm{a}}$, Andrey Yachmenev ${ }^{\mathrm{a}}$, Jonathan \\ Tennyson $^{\mathrm{a}}$, Walter Thiel $^{\mathrm{b}}$ \\ ${ }^{a}$ Department of Physics and Astronomy, University College London, Gower Street, \\ WC1E 6BT London, United Kingdom \\ ${ }^{b}$ Max-Planck-Institut für Kohlenforschung, Kaiser-Wilhelm-Platz 1, 45470 Mülheim an \\ der Ruhr, Germany
}

\begin{abstract}
A new dipole moment surface (DMS) for methyl chloride has been generated at the $\operatorname{CCSD}(\mathrm{T}) /$ aug-cc-pVQZ $(+\mathrm{d}$ for $\mathrm{Cl}$ ) level of theory. To represent the DMS, a symmetry-adapted analytic representation in terms of nine vibrational coordinates has been developed and implemented. Variational calculations of the infrared spectrum of $\mathrm{CH}_{3} \mathrm{Cl}$ show good agreement with a range of experimental results. This includes vibrational transition moments, absolute line intensities of the $\nu_{1}, \nu_{4}, \nu_{5}$ and $3 \nu_{6}$ bands, and a rotation-vibration line list for both $\mathrm{CH}_{3}{ }^{35} \mathrm{Cl}$ and $\mathrm{CH}_{3}{ }^{37} \mathrm{Cl}$ including states up to $J=85$ and vibrational band origins up to $4400 \mathrm{~cm}^{-1}$. Across the spectrum band shape and structure are well reproduced and computed absolute line intensities are comparable with highly accurate experimental measurements for certain fundamental bands. We thus recommend the DMS for future use. Keywords: Line-lists, Radiative transfer, Databases, HITRAN
\end{abstract}

Email address: alec.owens.130ucl.ac.uk (Alec Owens) 


\section{Introduction}

The proposal of methyl chloride as a potential biosignature gas [1-3] in the search for life outside of the Solar System has ignited interest in its infrared spectrum. There is now considerable motivation for a comprehensive rotation-vibration line list of $\mathrm{CH}_{3} \mathrm{Cl}$. Since methyl chloride is known to contribute to ozone depletion, any such line list would undoubtedly be useful in terrestrial studies. Its importance as an atmospheric molecule is confirmed by the huge number of recent spectroscopic studies [4-31].

The HITRAN database [32] has the most detailed coverage with over 212000 lines for the two main isotopologues, ${ }^{12} \mathrm{CH}_{3}{ }^{35} \mathrm{Cl}$ and ${ }^{12} \mathrm{CH}_{3}{ }^{37} \mathrm{Cl}$ (henceforth labelled as $\mathrm{CH}_{3}{ }^{35} \mathrm{Cl}$ and $\mathrm{CH}_{3}{ }^{37} \mathrm{Cl}$ ). This includes rovibrational transitions up to $J=82$ and covers the $0-3200 \mathrm{~cm}^{-1}$ region. However, there are deficiencies and we will see in Sec. 4.3 that HITRAN is missing a band around $2880 \mathrm{~cm}^{-1}$. Some line positions and intensities are also from theoretical predictions using a fairly old, empirically refined anharmonic force field [33]. Given the numerous high-resolution studies since then, notably in the $3.4 \mu \mathrm{m}$ region [4] (included in HITRAN2012) and in the $6.9 \mu \mathrm{m}$ region [14], improvements can be expected in the coverage of $\mathrm{CH}_{3} \mathrm{Cl}$. Another valuable resource is the PNNL spectral library [34] which covers the 600 to $6500 \mathrm{~cm}^{-1}$ region at a resolution of around $0.06 \mathrm{~cm}^{-1}$ for temperatures of 5 , 25 and $50^{\circ} \mathrm{C}$. Other databases such as GEISA [35] include $\mathrm{CH}_{3} \mathrm{Cl}$ but the datasets are not as extensive, whilst the JPL [36] catalog has been incorporated into HITRAN.

Intensity information is vital for practical applications such as atmospheric modelling or remote sensing. The six fundamental bands of $\mathrm{CH}_{3} \mathrm{Cl}$ have all been considered at some stage [4, 14, 37-50]. Notably, absolute line intensities have been measured for the $\nu_{1}, \nu_{4}$ and $3 \nu_{6}$ bands in the 2920 
to $3100 \mathrm{~cm}^{-1}$ range [4], and for over 900 rovibrational transitions in the $\nu_{5}$ band [14]. These two studies are the most reliable and complete line intensity measurements for both $\mathrm{CH}_{3}{ }^{35} \mathrm{Cl}$ and $\mathrm{CH}_{3}{ }^{37} \mathrm{Cl}$ to date. From a theoretical perspective, calculations of dipole moment derivatives and infrared intensities have been reported $[27,33,51-57]$. However, we are unaware of any global DMS which could be used for intensity simulations of the rotation-vibration spectrum of $\mathrm{CH}_{3} \mathrm{Cl}$.

Previously we reported [58] two state-of-the-art ab initio potential energy surfaces for the two main isotopologues of methyl chloride. Variational calculations of the vibrational $J=0$ energies and equilibrium geometry showed excellent agreement with experimental results. Building on this work, we present a new nine-dimensional ab initio DMS which has been computed using high-level electronic structure theory. A symmetrized molecular bond (SMB) representation for $\mathrm{XY}_{3} \mathrm{Z}$-type molecules has been implemented into the nuclear motion code TROVE [59] to represent the DMS analytically. Comprehensive calculations of the rotation-vibration spectrum are then carried out to evaluate the quality of the DMS. The work presented here represents the next step towards generating a complete rovibrational line list applicable for elevated temperatures.

The paper is structured as follows: In Sec. 2 the electronic structure calculations and analytic representation of the DMS are described. Details of the variational calculations are given in Sec. 3. In Sec. 4 the DMS is evaluated against a range of experimental measurements as well as the HITRAN and PNNL spectroscopic databases. Results include vibrational transition moments, absolute line intensities of the $\nu_{1}, \nu_{4}, \nu_{5}$ and $3 \nu_{6}$ bands, and an overview of the rotation-vibration spectrum for states up to $J=85$ in the 0-6500 $\mathrm{cm}^{-1}$ frequency range. Concluding remarks are offered in Sec. 5. 


\section{Dipole Moment Surface}

\subsection{Electronic structure calculations}

The first derivative of the electronic energy with respect to external electric field strength defines the electric dipole moment of a molecule. Working in a Cartesian laboratory-fixed $X Y Z$ coordinate system with origin at the $\mathrm{C}$ nucleus, an external electric field with components \pm 0.005 a.u. was applied along each axis and the respective dipole moment component $\mu_{A}$ for $A=X, Y, Z$ determined using finite differences. Calculations were carried out at the $\operatorname{CCSD}(\mathrm{T})$ [coupled cluster with all single and double excitations and a perturbational estimate of connected triple excitations] level of theory with the augmented correlation consistent quadruple zeta basis set, aug-cc-pVQZ $(+\mathrm{d}$ for $\mathrm{Cl})$ [60-63], in the frozen core approximation. MOLPRO2012 [64] was used for all calculations.

The DMS was evaluated on a nine-dimensional global grid of 44,820 points with energies up to $h c \cdot 50000 \mathrm{~cm}^{-1}$ ( $h$ is the Planck constant and $c$ is the speed of light). The grid included geometries in the range $1.3 \leq r_{0} \leq 2.95 \AA$, $0.7 \leq r_{i} \leq 2.45 \AA, 65 \leq \beta_{i} \leq 165^{\circ}$ for $i=1,2,3$ and $55 \leq \tau_{j k} \leq 185^{\circ}$ with $j k=12,13$. Here, the nine internal coordinates are: the $\mathrm{C}-\mathrm{Cl}$ bond length $r_{0}$; three $\mathrm{C}-\mathrm{H}$ bond lengths $r_{1}, r_{2}$ and $r_{3}$; three $\angle\left(\mathrm{H}_{i} \mathrm{CCl}\right)$ interbond angles $\beta_{1}, \beta_{2}$ and $\beta_{3}$; and two dihedral angles $\tau_{12}$ and $\tau_{13}$ between adjacent planes containing $\mathrm{H}_{i} \mathrm{CCl}$ and $\mathrm{H}_{j} \mathrm{CCl}$. The grid utilized for the DMS is the same as that used for the PESs previously reported [58].

\subsection{Analytic representation}

Before fitting an analytic expression to the ab initio data it is necessary to establish a suitable molecule-fixed $x y z$ coordinate system. Methyl chloride is a prolate symmetric top molecule of the $\boldsymbol{C}_{3 \mathrm{v}}(\mathrm{M})$ symmetry group [65]. 
There are six symmetry operations $\left\{E,(123),(132),(12)^{*},(23)^{*},(13)^{*}\right\}$ which make up $\boldsymbol{C}_{3 \mathrm{v}}(\mathrm{M})$. The cyclic permutation operation (123) replaces nucleus 1 with nucleus 2 , nucleus 2 with nucleus 3 , and nucleus 3 with nucleus 1 ; the permutation-inversion operation (12)* interchanges nuclei 1 and 2 and inverts all particles (including electrons) in the molecular centre of mass; the identity operation $E$ leaves the molecule unchanged. The symmetrized molecular bond (SMB) representation has been successfully applied to molecules of $\boldsymbol{C}_{3 \mathrm{v}}(\mathrm{M})$ symmetry $[66,67]$ and this approach is employed for the present study.

We first define unit vectors along each of the four bonds of $\mathrm{CH}_{3} \mathrm{Cl}$,

$$
\mathbf{e}_{i}=\frac{\mathbf{r}_{i}-\mathbf{r}_{\mathrm{C}}}{\left|\mathbf{r}_{i}-\mathbf{r}_{\mathrm{C}}\right|} ; \quad i=0,1,2,3
$$

where $\mathbf{r}_{\mathrm{C}}$ is the position vector of the $\mathrm{C}$ nucleus, $\mathbf{r}_{0}$ the $\mathrm{Cl}$ nucleus, and $\mathbf{r}_{1}$, $\mathbf{r}_{2}$ and $\mathbf{r}_{3}$ the respective $\mathrm{H}$ atoms. The ab initio dipole moment vector $\boldsymbol{\mu}$ is projected onto the molecular bonds and can be described by molecule-fixed $x y z$ dipole moment components,

$$
\begin{aligned}
& \mu_{x}=\frac{1}{\sqrt{6}}\left(2\left(\boldsymbol{\mu} \cdot \mathbf{e}_{1}\right)-\left(\boldsymbol{\mu} \cdot \mathbf{e}_{2}\right)-\left(\boldsymbol{\mu} \cdot \mathbf{e}_{3}\right)\right), \\
& \mu_{y}=\frac{1}{\sqrt{2}}\left(\left(\boldsymbol{\mu} \cdot \mathbf{e}_{2}\right)-\left(\boldsymbol{\mu} \cdot \mathbf{e}_{3}\right)\right), \\
& \mu_{z}=\boldsymbol{\mu} \cdot \mathbf{e}_{0} .
\end{aligned}
$$

Symmetry-adapted combinations have been formed for $\mu_{x}$ and $\mu_{y}$ and these transform according to $E$ symmetry, while the $\mu_{z}$ component is of $A_{1}$ symmetry. The advantage of the SMB representation is that the unit vectors $\mathbf{e}_{i}$ used to define $\mu$ for any instantaneous positions of the nuclei are related to the internal coordinates only.

To construct the three dipole surfaces corresponding to the components given in Eqs. (2) to (4), a numerical, on-the-fly symmetrization procedure 
has been implemented. This is similar to the approach employed for the PES [58] but because $\boldsymbol{\mu}$ is a vector quantity we have to consider the transformation properties of the dipole moment components themselves. For $\mu_{z}$, which points along the $\mathrm{C}-\mathrm{Cl}$ bond, the process is trivial owing to its $A_{1}$ symmetry and invariance to the $\boldsymbol{C}_{3 \mathrm{v}}(\mathrm{M})$ symmetry operations. Building an analytic expression follows the same steps as the PES. For the two E symmetry components, $\mu_{x}$ and $\mu_{y}$, the construction is more subtle and they must be treated together.

We consider an initial (reference) term in the dipole expansion belonging to $\mu_{x}$

$$
\left(\begin{array}{l}
\mu_{x} \\
\mu_{y}
\end{array}\right)=\left(\begin{array}{c}
\mu_{x, i j k \ldots}^{\text {initial }} \\
0
\end{array}\right),
$$

where

$$
\mu_{x, i j k \ldots}^{\text {initial }}=\left(\xi_{1}^{i} \xi_{2}^{j} \xi_{3}^{k} \xi_{4}^{l} \xi_{5}^{m} \xi_{6}^{n} \xi_{7}^{p} \xi_{8}^{q} \xi_{9}^{r}\right)
$$

This term has maximum expansion order $i+j+k+l+m+n+p+q+r=6$, and is expressed in terms of the nine coordinates,

$$
\begin{aligned}
& \xi_{1}=\left(r_{0}-r_{0}^{\mathrm{ref}}\right), \\
& \xi_{j}=\left(r_{i}-r_{1}^{\mathrm{ref}}\right) ; j=2,3,4, i=j-1, \\
& \xi_{k}=\left(\beta_{i}-\beta^{\mathrm{ref}}\right) ; k=5,6,7, i=k-4, \\
& \xi_{8}=\frac{1}{\sqrt{6}}\left(2 \tau_{23}-\tau_{13}-\tau_{12}\right), \\
& \xi_{9}=\frac{1}{\sqrt{2}}\left(\tau_{13}-\tau_{12}\right) .
\end{aligned}
$$

Here, $\tau_{23}=2 \pi-\tau_{12}-\tau_{13}$ and the reference structural parameters $r_{0}^{\text {ref }}=$ $1.7550 \AA, r_{1}^{\mathrm{ref}}=1.0415 \AA$ and $\beta^{\mathrm{ref}}=108.414^{\circ}$. Note that the values of $r_{0}^{\mathrm{ref}}$, $r_{1}^{\mathrm{ref}}$ and $\beta^{\mathrm{ref}}$ were optimized during the fitting of the DMS.

The action of a symmetry operation $\mathbf{X}=\left\{E,(123),(132),(12)^{*},(23)^{*},(13)^{*}\right\}$ on Eq. (6) will (i) permute the expansion indices $i j k \ldots$, to $i^{\prime} j^{\prime} k^{\prime} \ldots$ to pro- 
duce a new expansion term and (ii) permute the unit vectors $\mathbf{e}_{i}$ for $i=1,2,3$. Using the projection operator technique [65], this latter contribution is projected onto the $\mathbf{e}_{x}$ and $\mathbf{e}_{y}$ molecule-fixed vectors and added to the respective dipole moment components. The resulting components, $\mu_{x}^{\prime}$ and $\mu_{y}^{\prime}$, reduce to

$$
\left(\begin{array}{c}
\mu_{x}^{\prime} \\
\mu_{y}^{\prime}
\end{array}\right)=\left(\begin{array}{l}
C_{1} \mu_{x, i j k \ldots}^{\mathbf{X}} \\
C_{2} \mu_{x, i j k \ldots}^{\mathbf{X}}
\end{array}\right),
$$

where $C_{1}$ and $C_{2}$ are constants associated with the acting $C_{3 \mathrm{v}}(\mathrm{M})$ symmetry operation, and $\mu_{x, i j k \ldots}^{\mathbf{X}}$ is the new expansion term connected to Eq. (6) by the symmetry operation $\mathbf{X}$. Note that a contribution arises in $\mu_{y}^{\prime}\left(C_{2} \neq 0\right)$ due to the projection operator acting on the two-component quantity $\left(\mu_{x}, \mu_{y}\right)$.

The steps are repeated for each symmetry operation of $\boldsymbol{C}_{3 \mathrm{v}}(\mathrm{M})$ and the results summed to produce a final dipole term (ignoring constants),

$$
\mu_{x, i j k \ldots}^{\mathrm{final}}=\mu_{x, i j k \ldots}^{E}+\mu_{x, i j k \ldots}^{(123)}+\mu_{x, i j k \ldots}^{(132)}+\mu_{x, i j k \ldots}^{(12)^{*}}+\mu_{x, i j k \ldots}^{(23)^{*}}+\mu_{x, i j k \ldots}^{(13)^{*}},
$$

which is best understood as a sum of symmetrized combinations of different permutations of coordinates $\xi_{i}$. Likewise, a similar expression contributes to $\mu_{y}$. Although we have only considered an initial term belonging to $\mu_{x}$, the same idea applies to initial terms belonging to $\mu_{y}$. Incorporating $\mu_{z}$ into the procedure is straightforward, thus enabling the simultaneous construction of all three dipole moment surfaces of $\mathrm{CH}_{3} \mathrm{Cl}$. Each surface is represented by the analytic expression

$$
\mu_{\alpha}^{\mathrm{total}}\left(\xi_{1}, \xi_{2}, \xi_{3}, \xi_{4}, \xi_{5}, \xi_{6}, \xi_{7}, \xi_{8}, \xi_{9}\right)=\sum_{i j k \ldots} F_{i j k \ldots}^{(\alpha)} \mu_{\alpha, i j k \ldots}^{\mathrm{final}}
$$

where some of the expansion coefficients $F_{i j k \ldots}^{(\alpha)}$ are shared between the $x$ and $y$ components.

A least squares fitting to the $a b$ initio data utilizing Watson's robust fitting scheme [68] was employed to determine $F_{i j k \ldots}^{(\alpha)}$ for $\alpha=x, y, z$. Weight 
factors of the form [69],

$$
w_{i}=\left(\frac{\tanh \left[-0.0006 \times\left(\tilde{E}_{i}-15000\right)\right]+1.002002002}{2.002002002}\right) \times \frac{1}{N \tilde{E}_{i}^{(w)}}
$$

were used in the fitting, with normalization constant $N=0.0001$ and $\tilde{E}_{i}^{(w)}=$

$\max \left(\tilde{E}_{i}, 10000\right)$, where $\tilde{E}_{i}$ is the potential energy at the $i$ th geometry above equilibrium (all values in $\mathrm{cm}^{-1}$ ). At geometries where $r_{0} \geq 2.35 \AA$, or $r_{i} \geq 2.00 \AA$ for $i=1,2,3$, the weights were decreased by several orders of magnitude. This was done because the coupled cluster method is known to become unreliable at very large stretch coordinates, indicated by a T1 diagnostic value $>0.02[70]$. Whilst the energies are not wholly accurate at these points, they ensure the DMS maintains a reasonable shape towards dissociation.

The three dipole surfaces for $\mu_{x}, \mu_{y}$ and $\mu_{z}$ employed sixth order expansions and used 175, 163 and 235 parameters, respectively. A combined weighted root-mean-square $(\mathrm{rms})$ error of $9 \times 10^{-5} \mathrm{D}$ was obtained for the fitting. Incorporating the analytic representation into variational nuclear motion calculations is relatively straightforward and the implementation requires only a small amount of code. The dipole expansion parameters along with a FORTRAN routine to construct the DMS are provided in the supplementary material.

\section{Variational calculations}

The nuclear motion program TROVE [59] was employed for all rovibrational calculations and details of the general methodology can be found elsewhere $[59,66,71]$. Since methyl chloride has already been treated using TROVE [58], we summarize only the key aspects of our calculations. 
An automatic differentiation method [71] was used to construct the rovibrational Hamiltonian numerically. The Hamiltonian itself was represented as a power series expansion around the equilibrium geometry in terms of nine vibrational coordinates. The coordinates used are almost identical to those given in Eqs. (7) to (11), except for the potential energy operator where Morse oscillator functions replace the linear expansion variables for stretching modes. In all calculations the kinetic and potential energy operators were truncated at 6th and 8th order, respectively. This level of truncation is adequate for our purposes (see Ref. [59] and [71] for a discussion of the associated errors of such a scheme). Atomic mass values were employed throughout.

Two purely ab initio PESs [58], CBS-35 ${ }^{\mathrm{HL}}$ and CBS-37 ${ }^{\mathrm{HL}}$, corresponding to the two main isotopologues, $\mathrm{CH}_{3}{ }^{35} \mathrm{Cl}$ and $\mathrm{CH}_{3}{ }^{37} \mathrm{Cl}$, have been utilized for the present study. The surfaces are based on extensive explicitly correlated coupled cluster calculations with extrapolation to the complete basis set (CBS) limit and include a range of additional higher-level energy corrections. The CBS-35 ${ }^{\mathrm{HL}}$ and $\mathrm{CBS}-37^{\mathrm{HL}}$ PESs reproduce the fundamental term values with rms errors of 0.75 and $1.00 \mathrm{~cm}^{-1}$, respectively. We are therefore confident that the DMS of $\mathrm{CH}_{3} \mathrm{Cl}$ can be evaluated accurately in conjunction with these PESs.

A multi-step contraction scheme [66] is used to construct the vibrational basis set and a polyad number truncation scheme controls its size. For $\mathrm{CH}_{3} \mathrm{Cl}$, we define the polyad number

$$
P=n_{1}+2\left(n_{2}+n_{3}+n_{4}\right)+n_{5}+n_{6}+n_{7}+n_{8}+n_{9} \leq P_{\max },
$$

and this does not exceed a predefined maximum value $P_{\max }$. Here, the quantum numbers $n_{k}$ for $k=1, \ldots, 9$ correspond to primitive basis functions $\phi_{n_{k}}$ for each vibrational mode. Multiplication with rigid-rotor eigenfunctions $\left|J, K, m, \tau_{\text {rot }}\right\rangle$ produces the final symmetrized basis set for use in $J>0$ cal- 
culations. The quantum number $K$ is the projection (in units of $\hbar$ ) of $J$ onto the molecule-fixed $z$-axis, whilst $\tau_{\text {rot }}$ determines the rotational parity as $(-1)^{\tau_{\text {rot }}}$. As we will see in Sec. 4, different sized basis sets have been utilized in this work and this reflects the computational demands of variational calculations of rovibrational spectra.

TROVE automatically assigns quantum numbers to the eigenvalues and corresponding eigenvectors by analysing the contribution of the basis functions. To be of spectroscopic use we map the vibrational quantum numbers $n_{k}$ to the normal mode quantum numbers $\mathrm{v}_{k}$ commonly used in spectroscopic studies. For $\mathrm{CH}_{3} \mathrm{Cl}$, vibrational states are labelled as $\mathrm{v}_{1} \nu_{1}+\mathrm{v}_{2} \nu_{2}+\mathrm{v}_{3} \nu_{3}+$ $\mathrm{v}_{4} \nu_{4}+\mathrm{v}_{5} \nu_{5}+\mathrm{v}_{6} \nu_{6}$ where $\mathrm{v}_{\mathrm{i}}$ counts the level of excitation.

The normal modes of methyl chloride are of $A_{1}$ or $E$ symmetry. The three non-degenerate modes have $A_{1}$ symmetry; the symmetric $\mathrm{CH}_{3}$ stretching mode $\nu_{1}\left(2967.77 / 2967.75 \mathrm{~cm}^{-1}\right)$, the symmetric $\mathrm{CH}_{3}$ deformation mode $\nu_{2}$ $\left(1354.88 / 1354.69 \mathrm{~cm}^{-1}\right)$ and the $\mathrm{C}-\mathrm{Cl}$ stretching mode $\nu_{3}\left(732.84 / 727.03 \mathrm{~cm}^{-1}\right)$.

Whilst the three degenerate modes have $E$ symmetry; the $\mathrm{CH}_{3}$ stretching mode $\nu_{4}^{\ell_{4}}\left(3039.26 / 3039.63 \mathrm{~cm}^{-1}\right)$, the $\mathrm{CH}_{3}$ deformation mode $\nu_{5}^{\ell_{5}}\left(1452.18 / 1452.16 \mathrm{~cm}^{-1}\right)$ and the $\mathrm{CH}_{3}$ rocking mode $\nu_{6}^{\ell_{6}}\left(1018.07 / 1017.68 \mathrm{~cm}^{-1}\right)$. The values in parentheses are the experimentally determined fundamental frequencies for $\mathrm{CH}_{3}{ }^{35} \mathrm{Cl}$ $/ \mathrm{CH}_{3}{ }^{37} \mathrm{Cl}[4,22]$. The additional vibrational angular momentum quantum numbers $\ell_{4}, \ell_{5}$ and $\ell_{6}$ are necessary to resolve the degeneracy of their respective modes. 


\section{Results}

\subsection{Vibrational transition moments}

As an initial test of the DMS we compute vibrational transition moments,

$$
\mu_{i f}=\sqrt{\sum_{\alpha=x, y, z}\left|\left\langle\Phi_{\mathrm{vib}}^{(f)}\left|\bar{\mu}_{\alpha}\right| \Phi_{\mathrm{vib}}^{(i)}\right\rangle\right|^{2}} .
$$

Here, $\left|\Phi_{\text {vib }}^{(i)}\right\rangle$ and $\left|\Phi_{\text {vib }}^{(f)}\right\rangle$ are the initial and final state vibrational $(J=0)$ eigenfunctions, respectively, and $\bar{\mu}_{\alpha}$ is the electronically averaged dipole moment function along the molecule-fixed axis $\alpha=x, y, z$.

Transition moments have been determined experimentally for the six fundamental modes of $\mathrm{CH}_{3}{ }^{35} \mathrm{Cl}$ and these are listed in Table 1 along with our computed values. Calculations employed a polyad truncation number of $P_{\max }=12$ which is sufficient for converging $\mu_{i f}$. Overall the agreement is encouraging and it indicates that the DMS should be reliable for intensity simulations of the fundamental bands.

For $\mathrm{CH}_{3}{ }^{37} \mathrm{Cl}$, band strength measurements of the $\nu_{3}$ [43] and $\nu_{6}$ [45] bands have been carried out but only minor differences were observed compared to $\mathrm{CH}_{3}{ }^{35} \mathrm{Cl}[40,44]$. Likewise, as seen in Table 1 the computed transition moments for the fundamentals only marginally differ compared to $\mathrm{CH}_{3}{ }^{35} \mathrm{Cl}$. It seems the intensity variation from isotopic substitution in methyl chloride is relatively small and in some instances almost negligible. A list of computed transitions moments from the vibrational ground state for 79 levels up to $4200 \mathrm{~cm}^{-1}$ is provided in the supplementary material. Note that for the equilibrium dipole moment of methyl chloride we calculate $\mu=1.8909 \mathrm{D}$ which is close to the experimental value of $\mu=1.8959(15) \mathrm{D}$ [72].

\subsection{Absolute line intensities of the $\nu_{1}, \nu_{4}, \nu_{5}$ and $3 \nu_{6}$ bands}

Recently, absolute line intensities were determined for the $\nu_{1}, \nu_{4}$ and $3 \nu_{6}$ bands around the $3.4 \mu \mathrm{m}$ region [4] (included in HITRAN2012), and 
Table 1: Calculated vibrational transition moments (in Debye) and frequencies (in $\mathrm{cm}^{-1}$ ) from the vibrational ground state for $\mathrm{CH}_{3}{ }^{35} \mathrm{Cl}$ and $\mathrm{CH}_{3}{ }^{37} \mathrm{Cl}$.

\begin{tabular}{ccccccc}
\hline \hline Mode & Sym. & Experiment & Calculated & $\mu_{i f}^{\text {calc }}$ & $\mu_{i f}^{\text {exp }}$ & Ref. \\
\hline & & & \multicolumn{5}{c}{$\mathrm{CH}^{3}{ }^{35} \mathrm{Cl}$} & & \\
$\nu_{1}$ & $A_{1}$ & 2967.77 & 2969.16 & 0.05296 & $0.053^{b}$ & Elkins et al. [41] \\
$\nu_{2}$ & $A_{1}$ & 1354.88 & 1355.01 & 0.05260 & $0.05006(1)^{c}$ & Blanquet et al. [49] \\
$\nu_{3}$ & $A_{1}$ & 732.84 & 733.22 & 0.11468 & $0.1121(8)$ & Dang-Nhu et al. [40] \\
$\nu_{4}$ & $E$ & 3039.26 & 3038.19 & 0.03108 & $0.033^{d}$ & Elkins et al. [41] \\
$\nu_{5}$ & $E$ & 1452.18 & 1452.56 & 0.05451 & $0.0527(7)$ & Cappellani et al. [42] \\
$\nu_{6}$ & $E$ & 1018.07 & 1018.05 & 0.03707 & $0.0388^{e}$ & Blanquet et al. [44] \\
& & & & $\mathrm{CH}_{3}{ }^{37} \mathrm{Cl}$ & & - \\
$\nu_{1}$ & $A_{1}$ & 2967.75 & 2969.14 & 0.05296 & - & - \\
$\nu_{2}$ & $A_{1}$ & 1354.69 & 1354.82 & 0.05275 & - & - \\
$\nu_{3}$ & $A_{1}$ & 727.03 & 727.40 & 0.11416 & - & - \\
$\nu_{4}$ & $E$ & 3039.63 & 3037.71 & 0.02939 & - & - \\
$\nu_{5}$ & $E$ & 1452.16 & 1452.53 & 0.05449 & - & - \\
$\nu_{6}$ & $E$ & 1017.68 & 1017.66 & 0.03724 & - & - \\
\hline \hline
\end{tabular}

${ }^{a}$ From Bray et al. [4] and Nikitin et al. [22]. ${ }^{b}$ From Papoušek et al. [56] but derived from band strength measurement of $S_{\mathrm{v}}=84.3 \pm 3.3 \mathrm{~cm}^{-2} \mathrm{~atm}^{-1}$ at $296 \mathrm{~K}$ [41]. ${ }^{c}$ Value of $\mu_{\nu_{2}}^{\exp }=0.0473(7) \mathrm{D}$ determined in Cappellani et al. [42]. ${ }^{d}$ From Papoušek et al. [56] but derived from band strength measurement of $S_{\mathrm{v}}=33.6 \pm 1.4 \mathrm{~cm}^{-2} \mathrm{~atm}^{-1}$ at $296 \mathrm{~K}$ [41]. ${ }^{e}$ From Papoušek et al. [56] but derived from band strength measurement of $S_{\mathrm{v}}=15.1 \pm$ $1.6 \mathrm{~cm}^{-2} \mathrm{~atm}^{-1}$ at $296 \mathrm{~K} \mathrm{[44].}$ 
for the $\nu_{5}$ band in the $6.9 \mu \mathrm{m}$ region [14]. To assess the DMS we compare against these works for both isotopologues up to $J=15$. Calculating higher rotational excitation is computationally demanding (rovibrational matrices scale linearly with $J$ ) so we set $P_{\max }=10$ which is sufficient for reliable intensities. A study on the five-atom molecule $\mathrm{SiH}_{4}$ [73], which has similar convergence properties with respect to $P_{\max }$, also employed $P_{\max }=10$ to produce intensities of the $\nu_{3}$ band with an estimated convergence error of $1 \%$ or less for transitions up to $J=16$. Because the two ab initio PESs used in this study, CBS- $35^{\mathrm{HL}}$ and CBS-37 ${ }^{\mathrm{HL}}$, can at best only be considered accurate to about $\pm 1 \mathrm{~cm}^{-1}$, for illustrative purposes we have shifted computed line positions to better match experiment in the following comparisons.

Absolute absorption intensities have been simulated at room temperature $(T=296 \mathrm{~K})$ using the expression,

$$
I(f \leftarrow i)=\frac{A_{i f}}{8 \pi c} g_{\mathrm{ns}}\left(2 J_{f}+1\right) \frac{\exp \left(-E_{i} / k T\right)}{Q(T) \nu_{i f}^{2}}\left[1-\exp \left(-\frac{h c \nu_{i f}}{k T}\right)\right],
$$

where $A_{i f}$ is the Einstein $A$ coefficient of a transition with frequency $\nu_{i f}$ between an initial state with energy $E_{i}$, and a final state with rotational quantum number $J_{f}$. Here, $k$ is the Boltzmann constant, $T$ is the absolute temperature and $c$ is the speed of light. The nuclear spin statistical weights are $g_{\mathrm{ns}}=\{16,16,16\}$ for states of symmetry $\left\{A_{1}, A_{2}, E\right\}$, respectively. These values have been calculated using the method detailed in Jensen and Bunker [74]. For the partition function we use values of $Q(T)=57,915.728$ and 58, 833.711 for $\mathrm{CH}_{3}{ }^{35} \mathrm{Cl}$ and $\mathrm{CH}_{3}{ }^{37} \mathrm{Cl}$, respectively [32]. Note that to ensure a correct comparison with the experimental studies of Bray et al. [4] and Barbouchi Ramchani et al. [14], the intensities of overlapping $A_{1}$ and $A_{2}$ spectral lines (listed as being of $A$ symmetry) must be halved.

In Fig. 1 we plot absolute line intensities for 126 transitions of the $\nu_{1}$ band and their corresponding residuals $\left(\%\left[\frac{\mathrm{obs}-\mathrm{calc}}{\mathrm{obs}}\right]\right)$ compared to measure- 

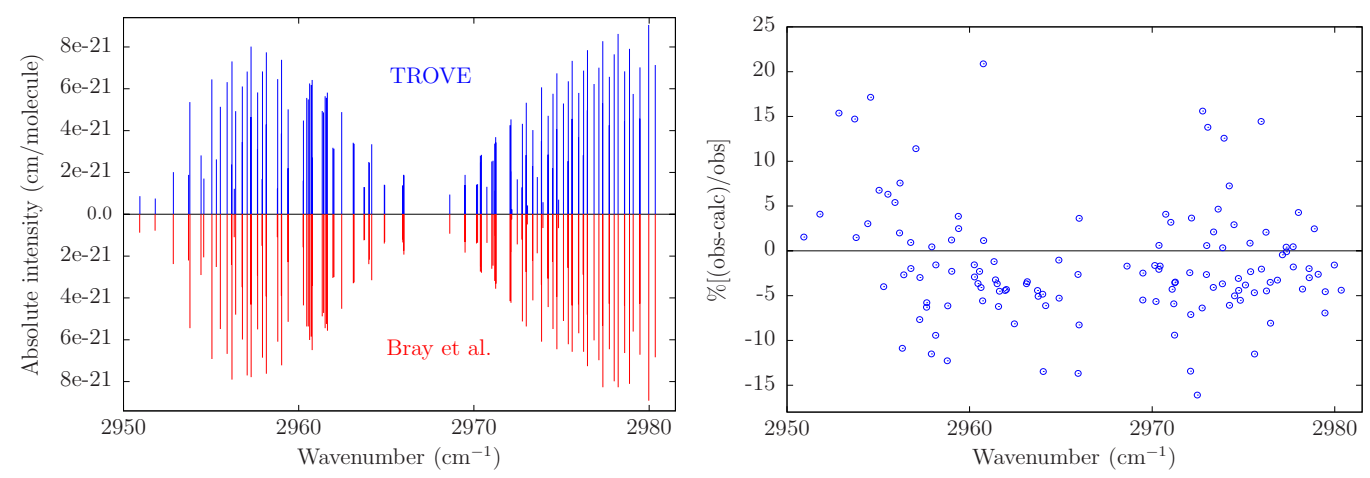

Figure 1: Absolute line intensities of the $\nu_{1}$ band for transitions up to $J=15$ (left) and the corresponding residuals (\% $\left.\left[\frac{\mathrm{obs}-\text { calc }}{\mathrm{obs}}\right]\right)$ (right) when compared with measurements from Bray et al. [4]. Transitions for both $\mathrm{CH}_{3}{ }^{35} \mathrm{Cl}$ and $\mathrm{CH}_{3}{ }^{37} \mathrm{Cl}$ are shown and the intensities have not been scaled to natural abundance. For illustrative purposes TROVE line positions have been shifted by $-1.35 \mathrm{~cm}^{-1}$.

ments from Bray et al. [4]. The majority of computed intensities, although tending to be marginally stronger, are within the experimental accuracy of $10 \%$ or better [75]. Calculated line positions had on average a residual error of $\Delta_{\text {obs-calc }}=-1.35 \mathrm{~cm}^{-1}$ and this has been corrected for in Fig. 1. Similarly, computed intensities of the $\nu_{4}$ band shown in Fig. 2 are largely within experimental uncertainty. Here, line positions possessed a residual error of $\Delta_{\text {obs-calc }}=-1.42 \mathrm{~cm}^{-1}$.

Line intensities of the $3 \nu_{6}$ band are shown in Fig. 3. Excited modes are harder to converge and the size of the vibrational basis set at $P_{\max }=10$ means the respective rovibrational energy levels have a convergence error of $1.0 \mathrm{~cm}^{-1}$ for low $J$ values (compared to errors of $\approx 0.1,0.5$ and $0.03 \mathrm{~cm}^{-1}$ for the $\nu_{1}, \nu_{4}$ and $\nu_{5}$ bands, respectively). The effect is that computed line intensities will have an uncertainty of around $5 \%$. Even so, the agreement for the 16 lines from Bray et al. [4] is good. Note that line positions displayed a residual error of $\Delta_{\text {obs-calc }}=-1.23 \mathrm{~cm}^{-1}$. 

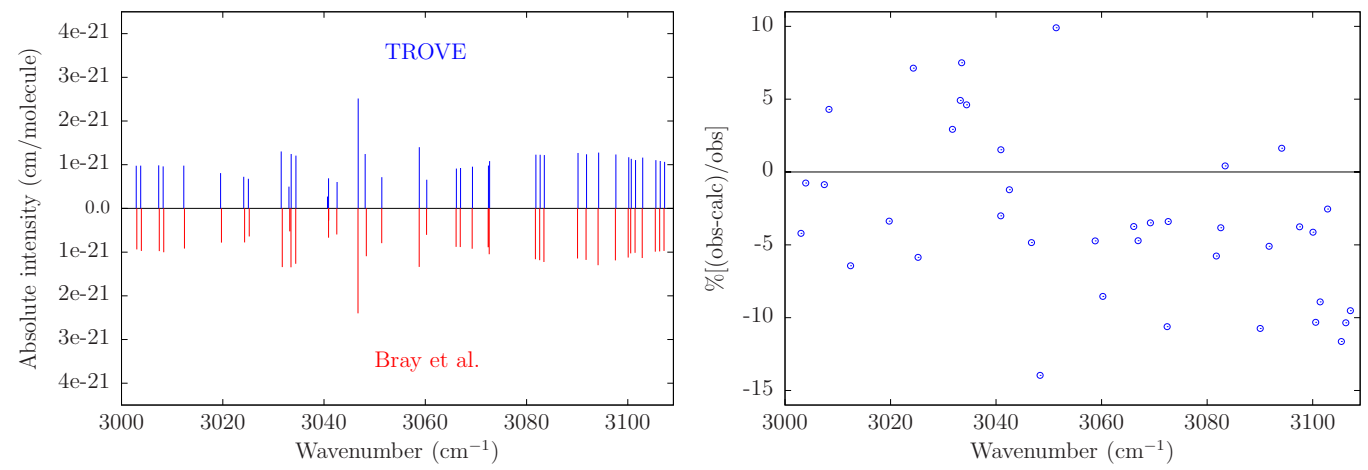

Figure 2: Absolute line intensities of the $\nu_{4}$ band for transitions up to $J=15$ (left) and the corresponding residuals (\% $\left.\left[\frac{\mathrm{obs}-\text { calc }}{\mathrm{obs}}\right]\right)$ (right) when compared with measurements from Bray et al. [4]. Transitions for both $\mathrm{CH}_{3}{ }^{35} \mathrm{Cl}$ and $\mathrm{CH}_{3}{ }^{37} \mathrm{Cl}$ are shown and the intensities have not been scaled to natural abundance. For illustrative purposes TROVE line positions have been shifted by $-1.42 \mathrm{~cm}^{-1}$.
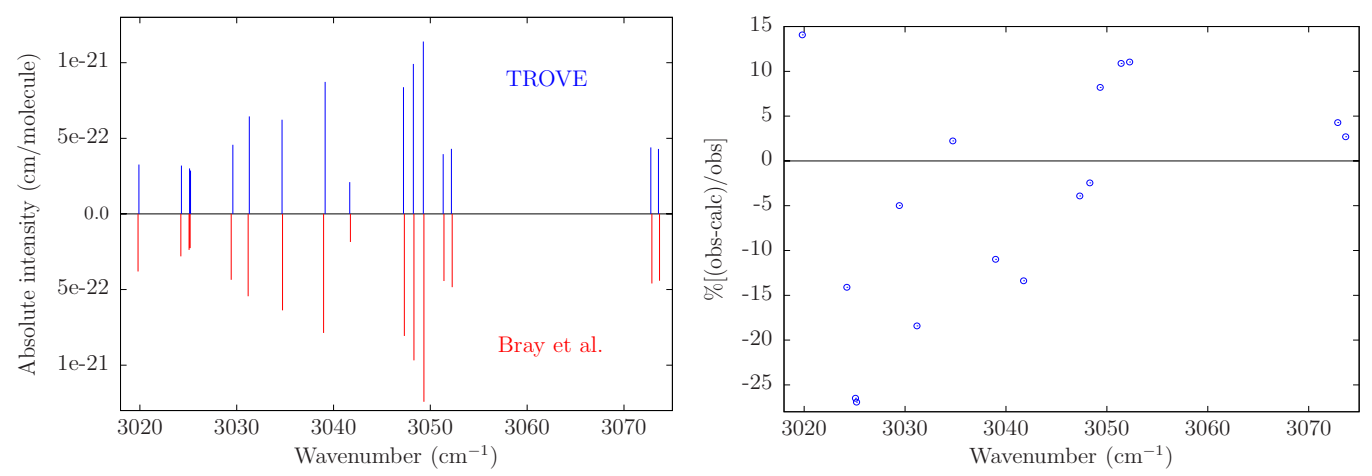

Figure 3: Absolute line intensities of the $3 \nu_{6}$ band for transitions up to $J=15$ (left) and the corresponding residuals (\% $\left.\left[\frac{\mathrm{obs}-\mathrm{calc}}{\mathrm{obs}}\right]\right)$ (right) when compared with measurements from Bray et al. [4]. Transitions for both $\mathrm{CH}_{3}{ }^{35} \mathrm{Cl}$ and $\mathrm{CH}_{3}{ }^{37} \mathrm{Cl}$ are shown and the intensities have not been scaled to natural abundance. For illustrative purposes TROVE line positions have been shifted by $-1.23 \mathrm{~cm}^{-1}$. 

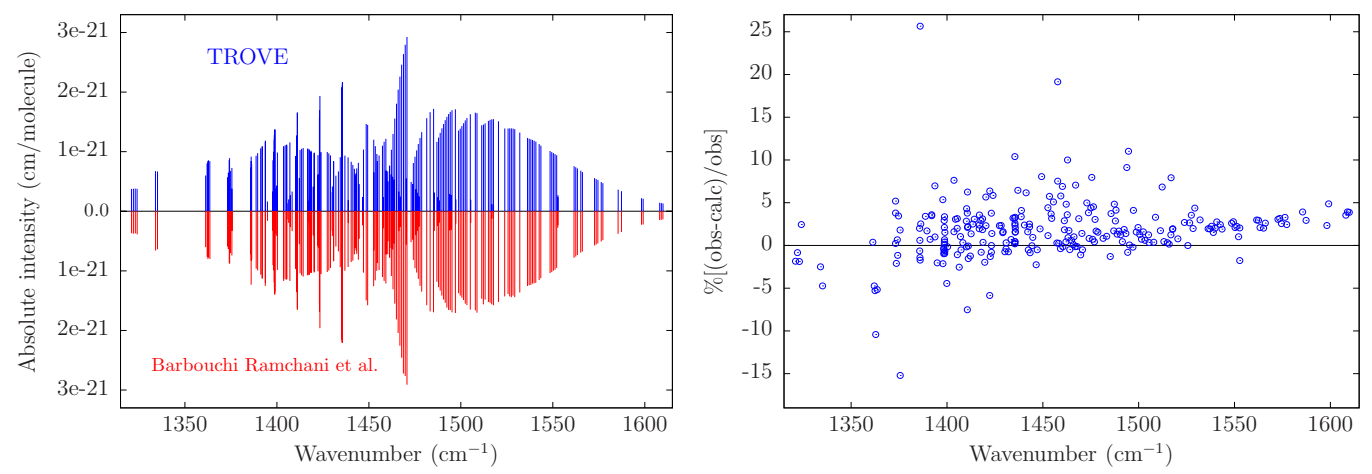

Figure 4: Absolute line intensities of the $\nu_{5}$ band for transitions up to $J=15$ (left) and the corresponding residuals (\% $\left.\left[\frac{\mathrm{obs}-\text { calc }}{\mathrm{obs}}\right]\right)$ (right) when compared with measurements from Barbouchi Ramchani et al. [14]. Transitions for both $\mathrm{CH}_{3}{ }^{35} \mathrm{Cl}$ and $\mathrm{CH}_{3}{ }^{37} \mathrm{Cl}$ are shown and the intensities have not been scaled to natural abundance. For illustrative purposes TROVE line positions have been shifted by $-0.40 \mathrm{~cm}^{-1}$.

A high-resolution study of the $\nu_{5}$ band measured absolute line intensities with an experimental accuracy of $5 \%$ or less, and line positions with an average estimated accuracy between $10^{-3}$ to $10^{-4} \mathrm{~cm}^{-1}$. As shown in Fig. 4 a significant number of computed line intensities are within experimental uncertainty and agreement for the 256 transitions up to $J=15$ is excellent. Here calculated line positions had a residual error of $\Delta_{\text {obs-calc }}=-0.40 \mathrm{~cm}^{-1}$.

\subsection{Overview of rotation-vibration line list}

The HITRAN database contains over 212000 lines for $\mathrm{CH}_{3} \mathrm{Cl}$ and considers transitions up to $J=82$. To compute such highly excited rovibrational energy levels it has been necessary to again reduce the size of the vibrational basis set. Calculations were carried out with $P_{\max }=8$ and an upper energy level cut-off of $8000 \mathrm{~cm}^{-1}$. Subsequent transitions and intensities were computed for a $6300 \mathrm{~cm}^{-1}$ frequency window with a lower state energy threshold of $4400 \mathrm{~cm}^{-1}$. Information has undoubtedly been lost by introducing these thresholds but the values were carefully chosen to keep this to a minimum. 
Such restrictions also allow the straightforward calculation of high $J$ values in a timely manner on compute nodes with $64 \mathrm{~GB}$ of RAM. Note that for pure rotational transitions in HITRAN the hyperfine structure has been resolved [76]. Therefore, in order to have a reliable comparison for this spectral region we scale our intensities by a factor of $1 / 2$.

In Fig. 5 we present a computed line list up to $J=85$ for both isotopologues of methyl chloride. Computed intensities have been scaled to natural abundance $\left(0.748937\right.$ for $\mathrm{CH}_{3}{ }^{35} \mathrm{Cl}$ and 0.239491 for $\mathrm{CH}_{3}{ }^{37} \mathrm{Cl}$ ) and are compared against all available lines in the HITRAN database. Overall the agreement is pleasing, particularly given the reduced size of the vibrational basis set and energy level thresholds. Up to $3200 \mathrm{~cm}^{-1}$ the only noticeable missing band in HITRAN appears to be the $2 \nu_{5}$ band around $2880 \mathrm{~cm}^{-1}$ shown in Fig. 6. This is not expected to be important for atmospheric sensing.

An improved spectroscopic line list in the range $1900-2600 \mathrm{~cm}^{-1}$ was recently published [23] and considered transitions up to $J=47$ with absolute line intensities possessing an estimated uncertainty of $20 \%$ or less. In Fig. 7 a comparison of this region, which is composed of several weak bands, is shown for $\mathrm{CH}_{3}{ }^{35} \mathrm{Cl}$. The DMS appears reasonable for much weaker intensities and the overall band structure in this region is well reproduced. There are some irregularities between TROVE and Nikitin et al. [23]; we expect these are caused by the low-level nature of our calculations and also the assignment procedure in TROVE. In future work we intend to carry out a more comprehensive analysis of this region. Note that the computed TROVE line list has not been truncated at $J=47$ for this comparison.

Whilst spectral features above $3200 \mathrm{~cm}^{-1}$ are not as prominent there are noticeable bands between $4300-4550 \mathrm{~cm}^{-1}$ and $5700-6200 \mathrm{~cm}^{-1}$ as shown in Fig. 8. Here we have compared against the PNNL spectral library [34] 


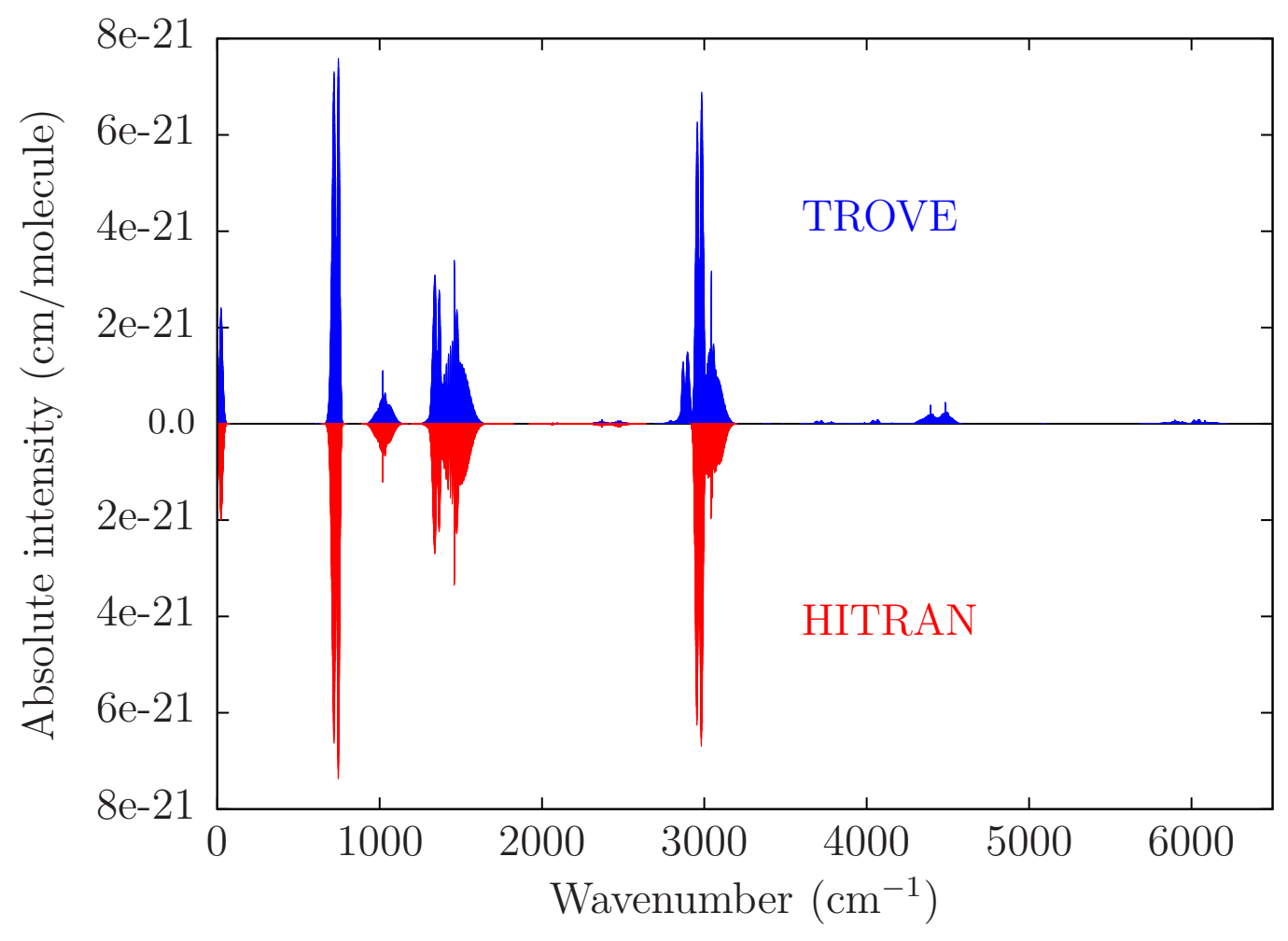

Figure 5: Overview of methyl chloride rotation-vibration line list up to $J=85$ compared with all transitions in the HITRAN database [32]. Computed intensities have been scaled to natural abundance.

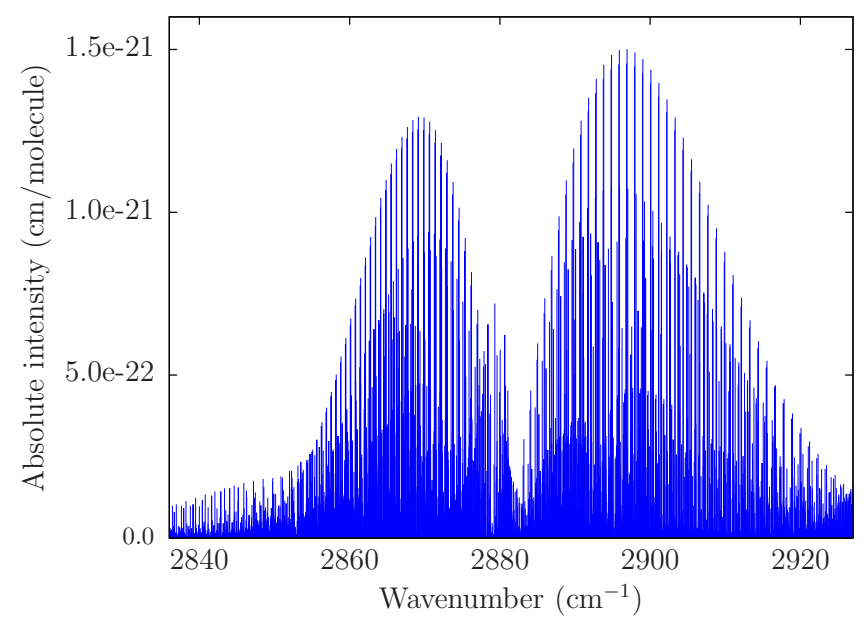

Figure 6: The $2 \nu_{5}$ band of methyl chloride. Computed intensities have been scaled to natural abundance. 


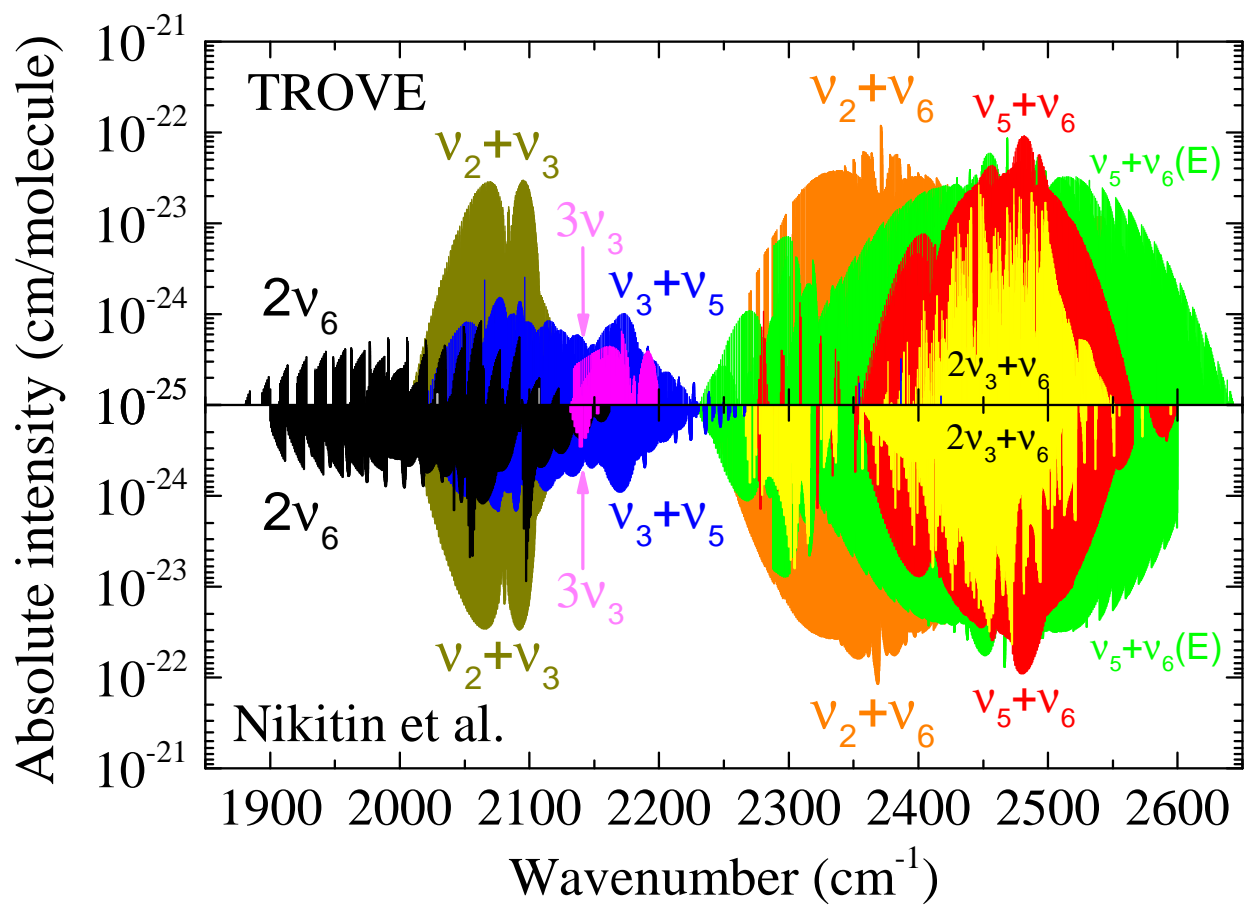

Figure 7: Absolute line intensities of $\mathrm{CH}_{3}{ }^{35} \mathrm{Cl}$ in the range $1900-2600 \mathrm{~cm}^{-1}$ compared with measurements from Nikitin et al. [23]. Computed TROVE transitions are up to $J=85$ whilst the results from Nikitin et al. [23] are up to $J=47$. Note that a logarithmic scale has been used for the y-axis. 

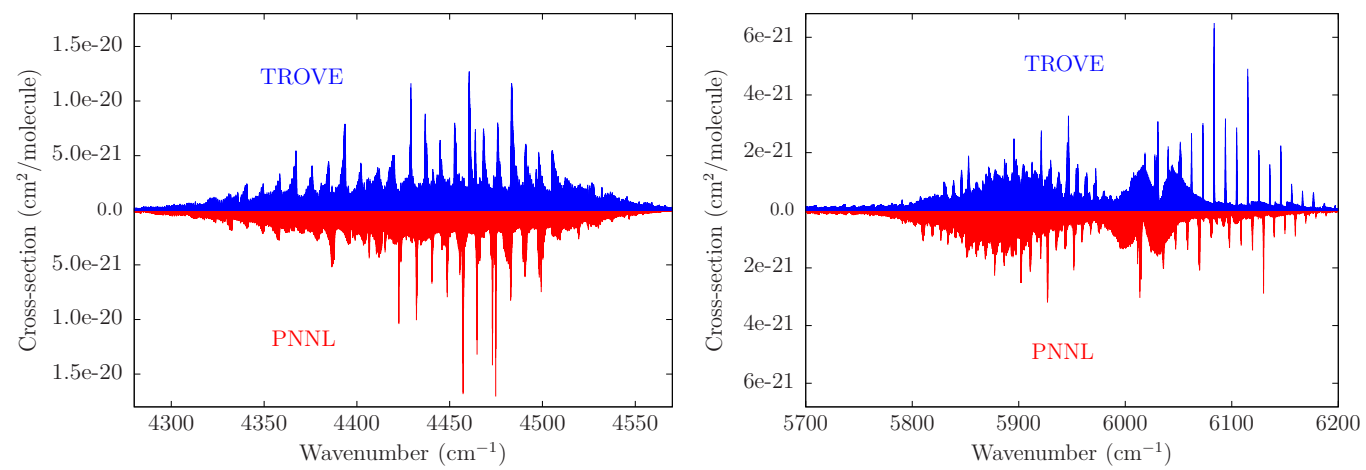

Figure 8: Overview of simulated rotation-vibration spectrum in the $4300-4550 \mathrm{~cm}^{-1}$ (left) and 5700-6200 $\mathrm{cm}^{-1}$ (right) regions compared with the PNNL spectral library [34]. Computed intensities have been scaled to natural abundance.

(overview of entire spectrum presented in Fig. 9). Cross sections have been generated at a resolution of $0.06 \mathrm{~cm}^{-1}$ and fitted using a Gaussian profile with a half width at half maximum of $0.112 \mathrm{~cm}^{-1}$. This line shape provides a straightforward and reasonable comparison [77], however, we expect a Voigt profile dependent on instrumental factors would be more suitable.

Looking at Fig. 8 it is clear that our calculations are becoming worse at higher energies and producing spurious intensities. This is to be expected given the size of the vibrational basis set and thresholds imposed in our variational calculations. For the complete spectrum in Fig. 9 the agreement with PNNL is encouraging but does indicate the need for improved computations and line shape modelling.

\section{Conclusions}

A new nine-dimensional DMS for methyl chloride has been computed using high-level $a b$ initio theory and fitted with a symmetry-adapted analytic representation. The DMS has been utilized to simulate the rotationvibration spectrum of methyl chloride up to $6300 \mathrm{~cm}^{-1}$. Overall, band shape 


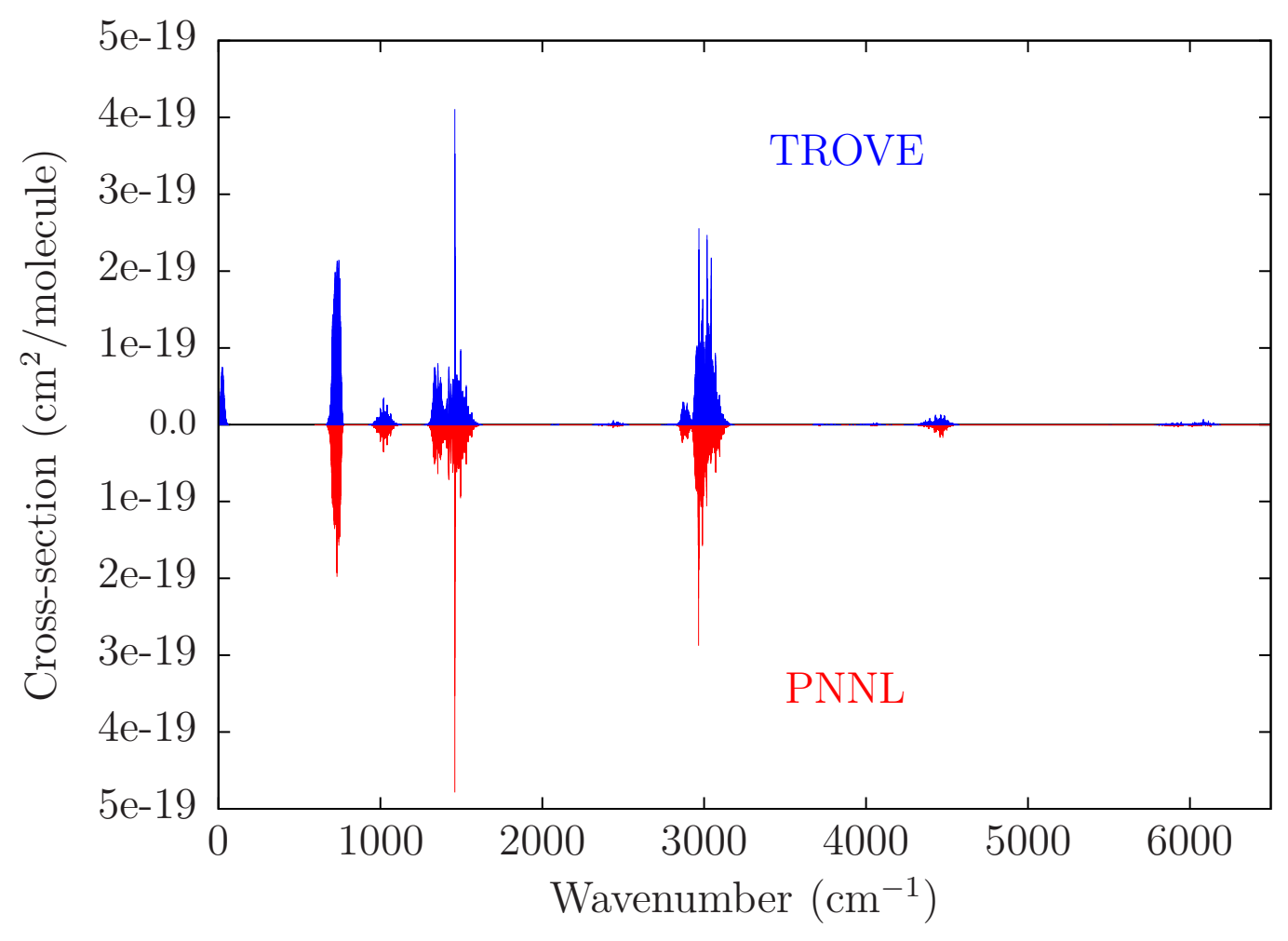

Figure 9: Overview of methyl chloride rotation-vibration spectrum up to $J=85$ compared with the PNNL spectral library [34]. Computed intensities have been scaled to natural abundance. 
and structure are well reproduced and there is good agreement with a range of experimental sources. Notably, at least for fundamental bands that have been measured with high accuracy, computed absolute line intensities agree well with the available experimental data.

Considering the quality of the DMS and intensity simulations, further improvements could come from using a larger (augmented) basis set for the electronic structure calculations. However, this would be very computationally demanding and the change in predicted intensities may not necessarily reflect the computational effort. Empirical refinement of the PES [78] is expected to produce more reliable intensities [79] (as a result of better rovibrational energy levels and associated wavefunctions) and should thus be done when attempting to produce a line list suitable for high-resolution spectroscopy.

Most beneficial though will be improvements in the variational nuclear motion calculations. This will require increasing both the size of the vibrational basis set and the frequency range considered. Measurements of absolute line intensities of the order $10^{-26}-10^{-27} \mathrm{~cm} /$ molecule have been reported in the 11590-11760 $\mathrm{cm}^{-1}$ spectral region [26]. Presently we are unable to accurately model such high frequencies; this is a major challenge for variational calculations on small polyatomic molecules. We expect these issues to be addressed during the construction of a comprehensive, hot line list for inclusion in the ExoMol database [80, 81].

\section{Acknowledgements}

The authors are grateful to Agnes Perrin and David Jacquemart for discussing results concerning their intensity measurements. This work was supported by ERC Advanced Investigator Project 267219, and FP7-MC-IEF project 629237 . 


\section{References}

[1] A. Segura, J. F. Kasting, V. Meadows, M. Cohen, J. Scalo, D. Crisp, R. A. H. Butler, G. Tinetti, Biosignatures from Earthlike planets around M dwarfs, Astrobiology 5 (2005) 706-725, doi: 10.1089/ast.2005.5.706.

[2] S. Seager, W. Bains, R. Hu, A biomass-based model to estimate the plausibility of exoplanet biosignature gases, Astrophys. J. 775 (2013) 104, doi:10.1088/0004-637X/775/2/104.

[3] S. Seager, W. Bains, R. Hu, Biosignature gases in $\mathrm{H}_{2}$-dominated atmospheres on rocky exoplanets, Astrophys. J. 777 (2013) 95, doi: 10.1088/0004-637X/777/2/95.

[4] C. Bray, A. Perrin, D. Jacquemart, N. Lacome, The $\nu_{1}, \nu_{4}$ and $3 \nu_{6}$ bands of methyl chloride in the $3.4-\mu \mathrm{m}$ region: Line positions and intensities, J. Quant. Spectrosc. Radiat. Transf. 112 (2011) 2446-2462, doi:10.1016/j.jqsrt.2011.06.018.

[5] C. Bray, H. Tran, D. Jacquemart, N. Lacome, Line mixing in the ${ }^{Q} \mathrm{Q}$ sub branches of the $\nu_{1}$ band of methyl chloride, J. Quant. Spectrosc. Radiat. Transf. 113 (2012) 2182-2188, doi:10.1016/j.jqsrt.2012.07.026.

[6] C. Bray, D. Jacquemart, J. Buldyreva, N. Lacome, A. Perrin, $\mathrm{N}_{2}$ broadening coefficients of methyl chloride at room temperature, J. Quant. Spectrosc. Radiat. Transf. 113 (2012) 1102-1112, doi: 10.1016/j.jqsrt.2012.01.028.

[7] C. Bray, D. Jacquemart, N. Lacome, M. Guinet, A. Cuisset, S. Eliet, F. Hindle, G. Mouret, F. Rohart, J. Buldyreva, Analysis of selfbroadened pure rotational and rovibrational lines of methyl chloride at 
room temperature, J. Quant. Spectrosc. Radiat. Transf. 116 (2013) 87100, doi:10.1016/j.jqsrt.2012.09.013.

[8] C. Bray, D. Jacquemart, N. Lacome, Temperature dependence for self- and $\mathrm{N}_{2}$-broadening coefficients of $\mathrm{CH}_{3} \mathrm{Cl}$, J. Quant. Spectrosc. Radiat. Transf. 129 (2013) 186-192, doi: http://dx.doi.org/10.1016/j.jqsrt.2013.06.013.

[9] M. Guinet, F. Rohart, J. Buldyreva, V. Gupta, S. Eliet, R. A. Motiyenko, L. Margulès, A. Cuisset, F. Hindle, G. Mouret, Experimental studies by complementary terahertz techniques and semi-classical calculations of $\mathrm{N}_{2}$ broadening coefficients of $\mathrm{CH}_{3}{ }^{35} \mathrm{Cl}$, J. Quant. Spectrosc. Radiat. Transf. 113 (2012) 1113-1126, doi:10.1016/j.jqsrt.2012.01.022.

[10] J. Buldyreva, M. Guinet, S. Eliet, F. Hindle, G. Mouret, R. Bocquet, A. Cuisset, Theoretical and experimental studies of $\mathrm{CH}_{3} \mathrm{X}-\mathrm{Y}_{2}$ rotational line shapes for atmospheric spectra modelling: application to roomtemperature $\mathrm{CH}_{3} \mathrm{Cl}-\mathrm{O}_{2}$, Phys. Chem. Chem. Phys. 13 (2011) 2032620334, doi:10.1039/c1cp22232e.

[11] J. Buldyreva, F. Rohart, Experimental and theoretical studies of roomtemperature sub-millimetre $\mathrm{CH}_{3}{ }^{35} \mathrm{Cl}$ line shapes broadened by $\mathrm{H}_{2}, \mathrm{Mol}$. Phys. 110 (2012) 2043-2053, doi:10.1080/00268976.2012.684895.

[12] J. Buldyreva, Air-broadening coefficients of $\mathrm{CH}_{3}{ }^{35} \mathrm{Cl}$ and $\mathrm{CH}_{3}{ }^{37} \mathrm{Cl}$ rovibrational lines and their temperature dependence by a semi-classical approach, J. Quant. Spectrosc. Radiat. Transf. 130 (2013) 315-320, doi: http://dx.doi.org/10.1016/j.jqsrt.2013.04.003.

[13] J. Buldyreva, L. Margulès, R. A. Motiyenko, F. Rohart, Speed dependence of $\mathrm{CH}_{3}{ }^{35} \mathrm{Cl}-\mathrm{O}_{2}$ line-broadening parameters probed on ro- 
tational transitions: Measurements and semi-classical calculations, J. Quant. Spectrosc. Radiat. Transf. 130 (2013) 304-314, doi: http://dx.doi.org/10.1016/j.jqsrt.2013.05.023.

[14] A. Barbouchi Ramchani, D. Jacquemart, M. Dhib, H. Aroui, Line positions, intensities and self-broadening coefficients for the $\nu_{5}$ band of methyl chloride, J. Quant. Spectrosc. Radiat. Transf. 120 (2013) 1-15, doi:10.1016/j.jqsrt.2013.02.002.

[15] A. Barbouchi Ramchani, D. Jacquemart, M. Dhib, H. Aroui, Theoretical calculation of self-broadening coefficients for the $\nu_{5}$ band of methyl chloride at various temperatures, J. Quant. Spectrosc. Radiat. Transf. 134 (2014) 1-8, doi:10.1016/j.jqsrt.2013.10.005.

[16] A. B. Ramchani, D. Jacquemart, M. Dhib, H. Aroui, $\mathrm{N}_{2}$ broadening coefficients of methyl chloride: Measurements at room temperature and calculations at atmospheric temperatures, J. Quant. Spectrosc. Radiat. Transf. 148 (2014) 186-196.

[17] A. S. Dudaryonok, N. N. Lavrentieva, J. V. Buldyreva, $\mathrm{CH}_{3} \mathrm{Cl}$ self-broadening coefficients and their temperature dependence, J. Quant. Spectrosc. Radiat. Transf. 130 (2013) 321-326, doi: http://dx.doi.org/10.1016/j.jqsrt.2013.07.013.

[18] A. S. Dudaryonok, N. N. Lavrentieva, J. Buldyreva, L. Margulès, R. A. Motiyenko, F. Rohart, Experimental studies, line-shape analysis and semi-empirical calculations of broadening coefficients for $\mathrm{CH}_{3}{ }^{35} \mathrm{Cl}-\mathrm{CO}_{2}$ submillimeter transitions, J. Quant. Spectrosc. Radiat. Transf. 145 (2014) 50-56, doi:10.1016/j.jqsrt.2014.04.015. 
[19] A. Nikitin, L. Féjard, J. P. Champion, H. Bürger, M. Litz, J. M. Colmont, B. Bakri, New measurements and global analysis of chloromethane in the region from 0 to $1800 \mathrm{~cm}^{-1}$, J. Mol. Spectrosc. 221 (2003) 199-212, doi:10.1016/S0022-2852(03)00221-2.

[20] A. Nikitin, J. P. Champion, H. Bürger, Global analysis of chloromethane: determinability of ground state constants, in: 14th Symposium on High-resolution Molecular Spectroscopy, vol. 5311 of SPIE Proceedings, 97-101, doi:10.1117/12.545197, 2004.

[21] A. Nikitin, J. P. Champion, New ground state constants of ${ }^{12} \mathrm{CH}_{3}{ }^{35} \mathrm{Cl}$ and ${ }^{12} \mathrm{CH}_{3}{ }^{37} \mathrm{Cl}$ from global polyad analysis, J. Mol. Spectrosc. 230 (2005) 168-173, doi:10.1016/j.jms.2004.11.012.

[22] A. Nikitin, J. P. Champion, H. Bürger, Global analysis of ${ }^{12} \mathrm{CH}_{3}{ }^{35} \mathrm{Cl}$ and ${ }^{12} \mathrm{CH}_{3}{ }^{37} \mathrm{Cl}$ : simultaneous fit of the lower five polyads $\left(0-2600 \mathrm{~cm}^{-1}\right), \mathrm{J}$. Mol. Spectrosc. 230 (2005) 174-184, doi:10.1016/j.jms.2004.11.012.

[23] A. V. Nikitin, T. A. Dmitrieva, I. E. Gordan, Improved spectroscopic line list of methyl chloride in the $1900-2600 \mathrm{~cm}^{-1}$ spectral region, J. Quant. Spectrosc. Radiat. Transf. 177 (2016) 49-58, doi: http://dx.doi.org/10.1016/j.jqsrt.2016.03.007.

[24] V. Gupta, F. Rohart, L. Margulès, R. A. Motiyenko, J. Buldyreva, Lineshapes and broadenings of rotational transitions of $\mathrm{CH}_{3}{ }^{35} \mathrm{Cl}$ in collision with He, Ar and Kr, J. Quant. Spectrosc. Radiat. Transf. 161 (2015) 85, doi:10.1016/j.jqsrt.2015.03.032.

[25] A.-L. Sahlberg, J. Zhou, M. Aldén, Z. S. Li, Non-intrusive in situ detection of methyl chloride in hot gas flows using infrared degenerate fourwave mixing, J. Raman Spectrosc. 46 (2015) 695, doi:10.1002/jrs.4651. 
[26] A. Lucchesini, S. Gozzini, Diode laser spectroscopy of methyl chloride overtones at 850-860 nm, J. Quant. Spectrosc. Radiat. Transf. 168 (2016) 170, doi:10.1016/j.jqsrt.2015.09.010.

[27] T. J. Wallington, B. P. Pivesso, A. M. Lira, J. E. Anderson, C. J. Nielsen, N. H. Andersen, Ø. Hodnebrog, $\mathrm{CH}_{3} \mathrm{Cl}, \mathrm{CH}_{2} \mathrm{Cl}_{2}, \mathrm{CHCl}_{3}$, and $\mathrm{CCl}_{4}$ : Infrared spectra, radiative efficiencies, and global warming potentials, J. Quant. Spectrosc. Radiat. Transf. 174 (2016) 56, ISSN 0022-4073, doi: http://dx.doi.org/10.1016/j.jqsrt.2016.01.029.

[28] R. Nassar, P. F. Bernath, C. D. Boone, C. Clerbaux, P. F. Coheur, G. Dufour, L. Froidevaux, E. Mahieu, J. C. McConnell, S. D. McLeod, D. P. Murtagh, C. P. Rinsland, K. Semeniuk, R. Skelton, K. A. Walker, R. Zander, A global inventory of stratospheric chlorine in 2004, J. Geophys. Res.-Atmos. 111 (2006) 13, doi:10.1029/2006JD007073.

[29] A. T. Brown, M. P. Chipperfield, C. Boone, C. Wilson, K. A. Walker, P. F. Bernath, Trends in atmospheric halogen containing gases since 2004, J. Quant. Spectrosc. Radiat. Transf. 112 (2011) 2552-2566, doi: 10.1016/j.jqsrt.2011.07.005.

[30] A. T. Brown, C. M. Volk, M. R. Schoeberl, C. D. Boone, P. F. Bernath, Stratospheric lifetimes of CFC-12, $\mathrm{CCl}_{4}, \mathrm{CH}_{4}, \mathrm{CH}_{3} \mathrm{Cl}$ and $\mathrm{N}_{2} \mathrm{O}$ from measurements made by the Atmospheric Chemistry Experiment-Fourier Transform Spectrometer (ACE-FTS), Atmos. Chem. Phys. 13 (2013) 6921-6950, doi:10.5194/acp-13-6921-2013.

[31] M. L. Santee, N. J. Livesey, G. L. Manney, A. Lambert, W. G. Read, Methyl chloride from the Aura Microwave Limb Sounder: First global climatology and assessment of variability in the upper troposphere and 
stratosphere, J. Geophys. Res.-Atmos. 118 (2013) 13532-13560, doi: 10.1002/2013JD020235.

[32] L. Rothman, I. Gordon, Y. Babikov, A. Barbe, D. C. Benner, P. Bernath, M. Birk, L. Bizzocchi, V. Boudon, L. Brown, A. Campargue, K. Chance, E. Cohen, L. Coudert, V. Devi, B. Drouin, A. Fayt, J.-M. Flaud, R. Gamache, J. Harrison, J.-M. Hartmann, C. Hill, J. Hodges, D. Jacquemart, A. Jolly, J. Lamouroux, R. L. Roy, G. Li, D. Long, O. Lyulin, C. Mackie, S. Massie, S. Mikhailenko, H. Müller, O. Naumenko, A. Nikitin, J. Orphal, V. Perevalov, A. Perrin, E. Polovtseva, C. Richard, M. Smith, E. Starikova, K. Sung, S. Tashkun, J. Tennyson, G. Toon, V. Tyuterev, G. Wagner, The HITRAN2012 molecular spectroscopic database, J. Quant. Spectrosc. Radiat. Transf. 130 (2013) 4-50, doi:http://dx.doi.org/10.1016/j.jqsrt.2013.07.002.

[33] S. Kondo, Y. Koga, T. Nakanaga, Infrared intensities in methyl chloride. III. Improvement of the anharmonic force field and the analysis of the overtone and combination band intensities, Bull. Chem. Soc. Jpn. 58 (1985) 65-72, doi:10.1246/bcsj.58.65.

[34] S. W. Sharpe, T. J. Johnson, R. L. Sams, P. M. Chu, G. C. Rhoderick, P. A. Johnson, Gas-phase databases for quantitative infrared spectroscopy, Appl. Spectrosc. 58 (2004) 1452-1461, doi: $10.1366 / 0003702042641281$.

[35] N. Jacquinet-Husson, L. Crepeau, R. Armante, C. Boutammine, A. Chédin, N. A. Scott, C. Crevoisier, V. Capelle, C. Boone, N. PouletCrovisier, A. Barbe, A. Campargue, D. C. Benner, Y. Benilan, B. Bézard, V. Boudon, L. R. Brown, L. H. Coudert, A. Coustenis, V. Dana, V. M. Devi, S. Fally, A. Fayt, J. M. Flaud, A. Gold- 
man, M. Herman, G. J. Harris, D. Jacquemart, A. Jolly, I. Kleiner, A. Kleinboehl, F. Kwabia-Tchana, N. Lavrentieva, N. Lacome, L.-H. Xu, O. M. Lyulin, J. Y. Mandin, A. Maki, S. Mikhailenko, C. E. Miller, T. Mishina, N. Moazzen-Ahmadi, H. S. P. Müller, A. Nikitin, J. Orphal, V. Perevalov, A. Perrin, D. T. Petkie, A. Predoi-Cross, C. P. Rinsland, J. J. Remedios, M. Rotger, M. A. H. Smith, K. Sung, S. Tashkun, J. Tennyson, R. A. Toth, A. C. Vandaele, J. Vander Auwera, The 2009 edition of the GEISA spectroscopic database, J. Quant. Spectrosc. Radiat. Transf. 112 (2011) 2395-2445, doi:10.1016/j.jqsrt.2011.06.004.

[36] H. M. Pickett, R. L. Poynter, E. A. Cohen, M. L. Delitsky, J. C. Pearson, H. S. P. Müller, Submillimeter, millimeter, and microwave spectral line catalog, J. Quant. Spectrosc. Radiat. Transf. 60 (1998) 883-890, doi: 10.1016/S0022-4073(98)00091-0.

[37] J. S. Margolis, R. A. Toth, Absorption strength measurement of the $\nu_{1}$ band of methyl chloride, J. Mol. Spectrosc. 66 (1977) 30-34, doi: 10.1016/0022-2852(77)90316-2.

[38] J. S. Margolis, Absorption strength of the perturbed $\nu_{4}$ band of $\mathrm{CH}_{3} \mathrm{Cl}$, J. Mol. Spectrosc. 70 (1978) 257-262, doi:10.1016/0022-2852(78)901601.

[39] M. Dang-Nhu, M. Morillon-Chapey, G. Graner, G. Guelachvili, Intensities of the $\nu_{1}$-bands of ${ }^{12} \mathrm{CH}_{3}{ }^{35} \mathrm{Cl}$ and ${ }^{12} \mathrm{CH}_{3}{ }^{37} \mathrm{Cl}$ near $3 \mu \mathrm{m}$, J. Quant. Spectrosc. Radiat. Transf. 26 (1981) 515-521, doi:10.1016/00224073(81)90038-8.

[40] M. Dang-Nhu, G. Blanquet, J. Walrand, F. Derie, Spectral intensities 
in the $\nu_{3}$-band of ${ }^{12} \mathrm{CH}_{3}{ }^{35} \mathrm{Cl}$ at $13 \mu \mathrm{m}$, Mol. Phys. 65 (1988) 77-83, doi: $10.1080 / 00268978800100861$.

[41] J. W. Elkins, R. H. Kagann, R. L. Sams, Infrared band strengths for methyl chloride in the regions of atmospheric interest, J. Mol. Spectrosc. 105 (1984) 480-490, doi:10.1016/0022-2852(84)90235-2.

[42] F. Cappellani, G. Restelli, G. Tarrago, Absolute infrared intensities in the fundamentals $\nu_{2}$ and $\nu_{5}$ of ${ }^{12} \mathrm{CH}_{3}{ }^{35} \mathrm{Cl}$, J. Mol. Spectrosc. 146 (1991) 326-333, doi:10.1016/0022-2852(91)90007-W.

[43] G. Blanquet, J. Walrand, M. Dang-Nhu, Spectral intensities in the $\nu_{3}$ band of ${ }^{12} \mathrm{CH}_{3}{ }^{37} \mathrm{Cl}$, J. Mol. Spectrosc. 133 (1989) 471-474, doi: 10.1016/0022-2852(89)90207-5.

[44] G. Blanquet, J. Walrand, M. Dang-Nhu, Absolute line intensities of the $\nu_{6}$ band of $\mathrm{CH}_{3}{ }^{35} \mathrm{Cl}$ at $10 \mu \mathrm{m}$, J. Mol. Spectrosc. 159 (1993) 156-160, doi:10.1006/jmsp.1993.1114.

[45] G. Blanquet, J. Walrand, M. Dang-Nhu, Intensities of the $\nu_{6}$ band of ${ }^{12} \mathrm{CH}_{3}{ }^{37} \mathrm{Cl}$ at $10 \mu \mathrm{m}$, J. Mol. Spectrosc. 162 (1993) 513-515, doi: 10.1006/jmsp.1993.1303.

[46] J. P. Bouanich, G. Blanquet, J. Walrand, Diode-laser measurements of self-broadening coefficients and line strengths in the $\nu_{3}$ band of $\mathrm{CH}_{3}{ }^{35} \mathrm{Cl}$, J. Quant. Spectrosc. Radiat. Transf. 51 (1994) 573-578, doi: 10.1016/0022-4073(94)90111-2.

[47] G. Blanquet, P. Coupe, J. Walrand, J. P. Bouanich, Determination of broadening coefficients and intensities for overlapping spectral lines with application to the ${ }^{Q} \mathrm{R}(3, \mathrm{~K})$ lines in the $\nu_{3}$ band of $\mathrm{CH}_{3}{ }^{35} \mathrm{Cl}$, J. 
Quant. Spectrosc. Radiat. Transf. 51 (1994) 671-678, doi:10.1016/00224073(94)90123-6.

[48] G. Blanquet, J. Walrand, J. C. Populaire, J. P. Bouanich, Selfbroadening coefficients and line strengths in the $\nu_{3}$ band of $\mathrm{CH}_{3}{ }^{35} \mathrm{Cl}$ at low temperature, J. Quant. Spectrosc. Radiat. Transf. 53 (1995) 211219, doi:10.1016/0022-4073(95)90008-X.

[49] G. Blanquet, B. Lance, J. Walrand, J. P. Bouanich, Absolute line intensities in the $\nu_{2}$ band of ${ }^{12} \mathrm{CH}_{3}{ }^{35} \mathrm{Cl}$ at $7.5 \mu \mathrm{m}$, J. Mol. Spectrosc. 170 (1995) 466-477, doi:10.1006/jmsp.1995.1085.

[50] G. Blanquet, B. Lance, J. Walrand, J. P. Bouanich, Absolute line intensities in the $\nu_{2}$ band of ${ }^{12} \mathrm{CH}_{3}{ }^{35} \mathrm{Cl}$ at $7.5 \mu \mathrm{m}$, Spectrochim. Acta, Part A 52 (1996) 1033-1035, doi:10.1016/0584-8539(95)01610-4.

[51] K. B. Wiberg, Infrared intensities. The methyl halides. Effect of substituents on charge distributions., J. Am. Chem. Soc. 101 (1979) 17181722, doi:10.1021/ja00501a012.

[52] S. Kondo, Y. Koga, T. Nakanaga, S. Saëki, Infrared intensities in methyl chloride. I. The fundamental bands, Bull. Chem. Soc. Jpn. 56 (1983) 416-421, doi:10.1246/bcsj.56.416.

[53] S. Kondo, Y. Koga, T. Nakanaga, S. Saëki, Infrared intensities in methyl chloride. II. Binary overtone and combination bands, Bull. Chem. Soc. Jpn. 57 (1984) 16-21, doi:10.1246/bcsj.57.16.

[54] W. Schneider, W. Thiel, Ab initio calculation of harmonic force fields and vibrational spectra for the methyl, silyl, germyl, and stannyl halides, J. Chem. Phys. 86 (1987) 923-936, doi:10.1063/1.452239. 
[55] D. P. Chong, D. Papoušek, Electric dipole moment derivatives for $\mathrm{PH}_{3}$, $\mathrm{PD}_{3}, \mathrm{CH}_{3} \mathrm{~F}, \mathrm{CD}_{3} \mathrm{~F}, \mathrm{CH}_{3} \mathrm{Cl}$, and $\mathrm{CD}_{3} \mathrm{Cl}$ computed by the density functional method, J. Mol. Spectrosc. 155 (1992) 167-176, ISSN 0022-2852, doi:10.1016/0022-2852(92)90556-4.

[56] D. Papoušek, Z. Papouškovà, D. P. Chong, Density functional computations of the dipole moment derivatives for halogenated methanes, J. Phys. Chem. 99 (1995) 15387-15395, doi:10.1021/j100042a010.

[57] A. F. Jalbout, B. Trzaskowski, Y. Xia, Y. Li, Geometry predictions, vibrational analysis and $\mathrm{IR}$ intensities of $\mathrm{XH}_{3} \mathrm{Y}(\mathrm{X}=\mathrm{C}, \mathrm{Si}, \mathrm{Ge}, \mathrm{Y}=\mathrm{F}$, $\mathrm{Cl}, \mathrm{Br}$ ) calculated by hybrid density functional theory, MP2 and MP4 methods, Acta Chim. Slov. 54 (2007) 769-777.

[58] A. Owens, S. N. Yurchenko, A. Yachmenev, J. Tennyson, W. Thiel, Accurate $a b$ initio vibrational energies of methyl chloride, J. Chem. Phys. 142 (2015) 244306, doi:10.1063/1.4922890.

[59] S. N. Yurchenko, W. Thiel, P. Jensen, Theoretical ROVibrational Energies (TROVE): A robust numerical approach to the calculation of rovibrational energies for polyatomic molecules, J. Mol. Spectrosc. 245 (2007) 126-140, doi:10.1016/j.jms.2007.07.009.

[60] T. H. Dunning Jr., Gaussian basis sets for use in correlated molecular calculations. 1. The atoms boron through neon and hydrogen, J. Chem. Phys. 90 (1989) 1007, doi:10.1063/1.456153.

[61] R. A. Kendall, T. H. Dunning Jr., R. J. Harrison, Electron affinities of the first-row atoms revisited. Systematic basis sets and wave functions, J. Chem. Phys. 96 (1992) 6796-6806, doi:10.1063/1.462569. 
[62] D. E. Woon, T. H. Dunning Jr., Gaussian basis sets for use in correlated molecular calculations. III. The atoms aluminum through argon, J. Chem. Phys. 98 (1993) 1358-1371, doi:10.1063/1.464303.

[63] T. H. Dunning Jr., K. A. Peterson, A. K. Wilson, Gaussian basis sets for use in correlated molecular calculations. X. The atoms aluminum through argon revisited, J. Chem. Phys. 114 (2001) 9244, doi: 10.1063/1.1367373.

[64] H.-J. Werner, P. J. Knowles, G. Knizia, F. R. Manby, M. Schütz, Molpro: a general-purpose quantum chemistry program package, WIREs Comput. Mol. Sci. 2 (2012) 242-253, doi:10.1002/wcms.82.

[65] P. R. Bunker, P. Jensen, Molecular Symmetry and Spectroscopy, NRC Research Press, Ottawa, 2nd edn., 1998.

[66] S. N. Yurchenko, R. J. Barber, A. Yachmenev, W. Thiel, P. Jensen, J. Tennyson, A variationally computed $T=300 \mathrm{~K}$ line list for $\mathrm{NH}_{3}, \mathrm{~J}$. Phys. Chem. A 113 (2009) 11845-11855, doi:10.1021/jp9029425.

[67] D. S. Underwood, J. Tennyson, S. N. Yurchenko, An ab initio variationally computed room-temperature line list for ${ }^{32} \mathrm{~S}^{16} \mathrm{O}_{3}$, Phys. Chem. Chem. Phys. 15 (2013) 10118-10125, doi:10.1039/c3cp50303h.

[68] J. K. G. Watson, Robust weighting in least-squares fits, J. Mol. Spectrosc. 219 (2003) 326-328, doi:10.1016/S0022-2852(03)00100-0.

[69] H. Partridge, D. W. Schwenke, The determination of an accurate isotope dependent potential energy surface for water from extensive ab initio calculations and experimental data, J. Chem. Phys. 106 (1997) 46184639, doi:10.1063/1.473987. 
[70] T. J. Lee, P. R. Taylor, A diagnostic for determining the quality of single-reference electron correlation methods, Int. J. Quantum Chem. 36 (1989) 199-207, doi:10.1002/qua.560360824.

[71] A. Yachmenev, S. N. Yurchenko, Automatic differentiation method for numerical construction of the rotational-vibrational Hamiltonian as a power series in the curvilinear internal coordinates using the Eckart frame, J. Chem. Phys. 143 (2015) 014105, doi:10.1063/1.4923039.

[72] G. Wlodarczak, B. Segard, J. Legrand, J. Demaison, The dipole moment of $\mathrm{CH}_{3}{ }^{35} \mathrm{Cl}$, J. Mol. Spectrosc. 111 (1985) 204-206, doi:10.1016/0022$2852(85) 90083-9$.

[73] A. Owens, S. N. Yurchenko, A. Yachmenev, W. Thiel, A global potential energy surface and dipole moment surface for silane, J. Chem. Phys. 143 (2015) 244317, doi:10.1063/1.4938563.

[74] P. Jensen, P. R. Bunker, Nuclear spin statistical weights revisited, Mol. Phys. 97 (1999) 821-824.

[75] D. Jacquemart, A. Perrin, private communication, 2016.

[76] M. Šimečkova, D. Jacquemart, L. S. Rothman, R. R. Gamache, A. Goldman, Einstein A-coefficients and statistical weights for molecular absorption transitions in the HITRAN database, J. Quant. Spectrosc. Radiat. Transf. 98 (2006) 130-155, doi:10.1016/j.jqrst.2005.07.003.

[77] A. F. Al-Refaie, A. Yachmenev, J. Tennyson, S. N. Yurchenko, ExoMol line lists VIII: A variationally computed line list for hot formaldehyde, Mon. Not. R. Astron. Soc. 448 (2015) 1704-1714, doi: 10.1093/mnras/stv091. 
[78] S. N. Yurchenko, R. J. Barber, J. Tennyson, W. Thiel, P. Jensen, Towards efficient refinement of molecular potential energy surfaces: Ammonia as a case study, J. Mol. Spectrosc. 268 (2011) 123-129, doi: 10.1016/j.jms.2011.04.005.

[79] R. I. Ovsyannikov, W. Thiel, S. N. Yurchenko, M. Carvajal, P. Jensen, $\mathrm{PH}_{3}$ revisited: Theoretical transition moments for the vibrational transitions below $7000 \mathrm{~cm}^{-1}$, J. Mol. Spectrosc. 252 (2008) 121-128, doi: 10.1016/j.jms.2008.07.005.

[80] J. Tennyson, S. N. Yurchenko, ExoMol: molecular line lists for exoplanet and other atmospheres, Mon. Not. R. Astron. Soc. 425 (2012) 21-33, doi:10.1111/j.1365-2966.2012.21440.x.

[81] J. Tennyson, S. N. Yurchenko, A. F. Al-Refaie, E. J. Barton, K. L. Chubb, P. A. Coles, S. Diamantopoulou, M. N. Gorman, C. Hill, A. Z. Lam, L. Lodi, L. K. McKemmish, Y. Na, A. Owens, O. L. Polyansky, C. Sousa-Silva, D. S. Underwood, A. Yachmenev, E. Zak, The ExoMol database: molecular line lists for exoplanet and other hot atmospheres, J. Mol. Spectrosc. (2016) . 